\title{
Produção de girassol ornamental e o uso de resíduo industrial como substrato
}

\author{
Ornamental sunflower production and the use of industrial waste as a substrate \\ Producción de girasol ornamental y uso de residuos industriales como sustrato
}

Recebido: 20/04/2021 | Revisado: 27/04/2021 | Aceito: 04/05/2021 | Publicado: 19/05/2021

\author{
Carolina Moreira de Medeiros \\ ORCID: https://orcid.org/0000-0002-3065-4422 \\ Universidade do Estado de Mato Grosso, Brasil \\ E-mail: karol_medeyros91@ @otmail.com \\ Petterson Baptista da Luz \\ ORCID: https://orcid.org/0000-0003-4067-0087 \\ Universidade do Estado de Mato Grosso, Brasil \\ E-mail: petterson@unemat.br
}

\begin{abstract}
Resumo
O girassol é uma planta versátil que apresenta inflorescências atrativas comercializadas como flor de corte ou vaso. Os objetivos do trabalho foram avaliar o cultivo do girassol ornamental em diferentes substratos e tamanhos de vasos, e verificar se esse cultivo corresponde o padrão de comercialização estabelecido pelo Veiling Holambra. O delineamento experimental utilizado foi inteiramente casualizado, em esquema fatorial 2x2 (dois substratos (comercial e resíduo de teca) e dois tamanhos de vasos (n. ${ }^{\circ} 10$ e 14), com 20 repetições, totalizando 80 vasos. Foram avaliados o diâmetro do caule, do capítulo interno e externo; altura da planta; número de folhas por planta e de botões, e período de durabilidade da inflorescência. Conclui-se que a combinação substrato comercial e o vaso $\mathrm{n}^{\circ} 14$ foi eficiente na produção de girassol ornamental. Em ambos os substratos testados as plantas se enquadraram no padrão de comercialização estabelecido para a espécie.
\end{abstract}

Palavras-chave: Helianthus annuus L.; Floricultura; Compostagem; Reciclagem.

\begin{abstract}
The sunflower is a versatile plant that has attractive inflorescences marketed as a cut flower or vase. The objectives of the work were to evaluate the cultivation of ornamental sunflower in different substrates and pot sizes, and to verify if this cultivation corresponds to the commercialization pattern established by Veiling Holambra. The experimental design used was completely randomized, in a $2 \times 2$ factorial scheme (two substrates (commercial and teak residue) and two vessel sizes $\left(\mathrm{n}^{\circ} 10\right.$ and 14$)$, with 20 replicates, totaling 80 vessels. The diameter of the stem, the internal and external chapter were evaluated; plant height; number of leaves per plant and buds, and period of durability of the inflorescence. It was concluded that the combination of commercial substrate and pot $\mathrm{n}^{\circ} 14$ was efficient in the production of ornamental sunflower. In both tested substrates, the plants fit the commercialization pattern established for the species.
\end{abstract}

Keywords: Helianthus annuus L.; Floriculture; Composting; Recycling.

\section{Resumen}

El girasol es una planta versátil que tiene atractivas inflorescencias comercializadas como flor cortada o jarrón. Los objetivos del trabajo fueron evaluar el cultivo de girasol ornamental en diferentes sustratos y tamaños de maceta, y verificar si este cultivo corresponde al patrón de comercialización establecido por Veiling Holambra. El diseño experimental utilizado fue completamente al azar, en un esquema factorial $2 \times 2$ (dos sustratos (comercial y residuo de teca) y dos tamaños de vasija ( $\mathrm{n}^{\circ} 10$ y 14), con 20 repeticiones, totalizando 80 vasijas. Se evaluó el diámetro del tallo, el capítulo interno y externo; altura de planta; número de hojas por planta y yemas, y período de durabilidad de la inflorescencia. Se concluyó que la combinación de sustrato comercial y maceta $\mathrm{n}^{\circ}$. 14 fue eficiente en la producción de girasol ornamental. En ambos sustratos probados, las plantas se ajustan al patrón de comercialización establecido para la especie.

Palabras clave: Helianthus annuиs L.; Floricultura; Compostaje; Reciclaje.

\section{Introdução}

O mercado de flores e plantas ornamentais tem crescido nos últimos anos, o país que se destaca nesse segmento é a Holanda, com maior volume de comercialização, tanto na importação quanto na exportação para o mundo. No Brasil, a produção de flores e plantas ornamentais tem como principal destino o mercado interno com $97 \%$ do total de volume comercializados (Neves \& Pinto, 2015). 
O setor de flores e plantas ornamentais movimenta a economia com cerca de $\mathrm{R} \$ 7,3$ bilhões com projeções otimistas de crescimento de 7\% a 9\% em 2018. A cidade de Holambra se destaca na produção e comercialização, com um aumento de $15 \%$ resultado esse superior ao resto do país (IBRAFLOR, 2018).

O girassol (Helianthus annuus L.) é uma planta herbácea, anual, ereta, folhas alternadas, pertencente à família Asteraceae, ordem Asterales. Sua inflorescência frequentemente chamada de 'flor' é do tipo capítulo (Rodrigues et al., 2012).

Apresenta sistema radicular pivotante (que pode atingir até $2 \mathrm{~m}$ de profundidade), sendo bastante ramificado na camada superficial do solo. Seu caule assume a forma de haste única podendo alcançar de 1 a $2 \mathrm{~m}$ de altura (Castiglioni et al.,1997; Lorenzi \& Souza, 2001). Possui inflorescência tipo capítulo que surge nas gemas apicais quando a planta é unicapitulada ou nas gemas laterais em plantas multicapituladas (Rodrigues et al., 2012).

Em meio a muitas espécies presentes no mercado da floricultura, o cultivo do girassol ornamental vem se convertendo em uma possibilidade de incremento de renda, podendo ser praticada em pequena e média propriedade, fornecendo ganho aos produtores, devido a suas características que incluem um ciclo curto, propagação por sementes e, especialmente em razão da exuberância e atração de suas inflorescências (Andrade et al., 2014). O seu potencial ornamental vem possibilitando a produção de flor de corte e de planta envasada, o que demanda variedades de porte baixo que propicie uma boa harmonia nos vasos (Barbosa et al., 2008). Os híbridos estéreis, que produzem pouco pólen, na atualidade são os cultivares mais utilizados no cultivo do girassol ornamental. No mercado de flores alguns dos híbridos disponíveis são: os 'Sunbright', 'Sunbright Supreme', 'Sunflower Red Sun' e 'Sunrich Orange' (Rodrigues et al., 2012).

Na produção de plantas, bons resultados são alcançados por meio de fatores que influenciam na formação de mudas de qualidade (Carvalho Filho et al., 2003). O tamanho do vaso e o tipo de substrato devem ser escolhidos conforme a necessidade da cultura, sendo importante que o vaso proporcione o bom desenvolvimento das raízes sem nenhuma restrição (Carvalho Filho et al., 2003). O volume de substrato a ser disponibilizado pode influenciar no desenvolvimento radicular, ou seja, essa limitação pode restringir o crescimento, a fotossíntese, a absorção de nutrientes, o florescimento e em consequência a produção (Seabra Júnior et al., 2004).

As agroindústrias produzem numerosos volumes de resíduos descartáveis os quais podem servir como componente de substrato orgânico, sendo o aproveitamento benéfico ao meio ambiente, além de garantir um material alternativo, de baixo custo e facilmente acessível (Lima et al., 2007). Em busca por aproveitamento de resíduos vegetais contribui para o produtor reduzir os custos de produção, além de evitar um descarte inadequado cooperando ambientalmente ademais com a capacidade de contribuir diretamente nas necessidades nutricionais das plantas durante todo o cultivo (Zanello \& Cardoso, 2016).

Deste modo, objetivos do trabalho foram avaliar o cultivo do girassol ornamental em diferentes substratos e tamanhos de vasos, e verificar se esse cultivo corresponde o padrão de comercialização estabelecido pelo Veiling Holambra.

\section{Metodologia}

O experimento foi desenvolvido no município de Cáceres, MT localizado nas coordenadas 1604'36.0"S latitude e $57^{\circ} 39^{\prime} 10.8^{\prime \prime} \mathrm{W}$ longitude em ambiente protegido (telado com malha de 50\% de sombreamento). A cultivar de girassol utilizado no cultivo foi o Sunflower Sunbright Kids, classificado como híbrido e os vasos utilizados no experimento foram os de $\mathrm{n}^{\mathrm{o}} 10 \mathrm{e}$ 14, com um volume de 0,50 L e 0,93 L respectivamente. Os substratos utilizados foram o comercial Vivatto Plus ${ }^{\circledR}$ e resíduo da indústria de serragem de teca (Tectona grandis L.f.), esse resíduo de serragem é um material oriundo da indústria madeireira que fica por anos amontoado e exposto ao tempo. No caso o material que utilizamos estava a dois anos amontoado, sofrendo decomposição. Na Tabela 1 podemos observar a análise dos dois materiais utilizados como substrato. Ambos os substratos receberam uma adubação mineral NPK 150-200-200 $\mathrm{mg} \mathrm{dm}^{-3}$ conforme (Neves et al., 2008). Logo após a homogeneização entre adubo e substrato ocorreu a distribuição nos vasos e, em seguida, a semeadura. 
Tabela 1. Atributos físicos dos diferentes materiais utilizados na produção de girassol Sunflower Sunbright Kids.

\begin{tabular}{cccccccccc}
\hline Amostra & PhH2O & CEmScm $^{-1}$ & DU kgm $^{-3}$ & DS kgm $^{-3}$ & PT \% & EA \% & AFD\% & AT \% & AR \% \\
\hline Comercial & 5,12 & 1,07 & 428,14 & 263,75 & 82,73 & 16,86 & 30,05 & 6,41 & 29,41 \\
Resíduo de Teca & 6,09 & 0,08 & 544,77 & 185,63 & 91,10 & 37,50 & 13,48 & 2,23 & 37,89 \\
\hline
\end{tabular}

DU = densidade úmida; $\mathrm{DS}=$ densidade seca; $\mathrm{pH}=$ determinado em água, diluição 1:5 (v/v); CE = condutividade elétrica obtida em solução $1: 5(\mathrm{v} / \mathrm{v})$. PT = porosidade total; EA = espaço de aeração; AFD = água facilmente disponível; AT = água tamponante; AR = Água remanescente. Fonte: Autores.

O delineamento experimental utilizado foi inteiramente casualizado, em esquema fatorial $2 \times 2$ (dois substratos (comercial e resíduo de teca) e dois tamanhos de vasos (n. ${ }^{\circ} 10$ e 14), com 20 repetições, totalizando 80 vasos.

A irrigação inicial ocorreu de forma automática por aspersão, posteriormente se manteve de forma manual, efetuada duas vezes ao dia ou conforme a necessidade da planta. Adotou-se semanalmente a reposição nutricional de macro e micronutrientes via fertirrigação de solução nutritiva de 25 gramas com a composição de nitrogênio $6 \%$, fósforo 18\%, potássio $12 \%$, cálcio $2 \%$, magnésio $2 \%$, enxofre $7 \%$, sulfato $2 \%$, boro $0,06 \%$, cobre $0,05 \%$, ferro $1,0 \%$, manganês $0,1 \%$, molibdênio $0,005 \%$ e zinco $0,2 \%$ dissolvido em $5 \mathrm{~L}$ de água e aplicados na quantidade de $0,15 \mathrm{~L}$ por vaso.

O controle de pragas e doenças foi realizado de maneira preventiva com uso de inseticida do grupo químico tiadiazinona e fungicida do grupo químico triazól.

Foram avaliados: diâmetro do caule $(\mathrm{mm})$, diâmetro do capítulo interno $(\mathrm{mm})$, diâmetro do capítulo externo $(\mathrm{mm}) \mathrm{e}$ as medidas foram aferidas com o uso de um paquímetro digital, para a determinação da altura da planta $(\mathrm{cm})$ foi utilizada uma régua graduada e o número de folhas por planta (un.), número de botões (un.) mediante contagem. O período de durabilidade da inflorescência (dias), foi avaliado visualmente durante o ciclo da cultura. A observação deu início quando as flores líguladas estavam totalmente expandidas e as flores tubulosas abertas até o momento do início da senescência que consiste na perda das pétalas, as chamadas flores liguladas.

Os resultados foram submetidos a análise de variância e teste $\mathrm{F}$ no nível de 5\% de probabilidade para comparação das médias, utilizando o programa estatístico SISVAR. (Ferreira, 2014). As características das plantas foram comparados ao padrão de comercialização estabelecido pelo Veiling Holambra, 2018.

\section{Resultados e Discussão}

As temperaturas e as umidades relativas do ar no decorrer do ciclo da cultura, 63 dias a contar da semeadura à senescência das inflorescências se manteve na faixa de temperaturas adequadas, as exigências climáticas da cultura. Os picos de máxima e mínima não prejudicaram o desenvolvimento do girassol (Figura 1). 
Figura 1. Médias de temperatura e umidade relativa do ar durante o ciclo da cultura do girassol ornamental na cidade de Cáceres - MT.

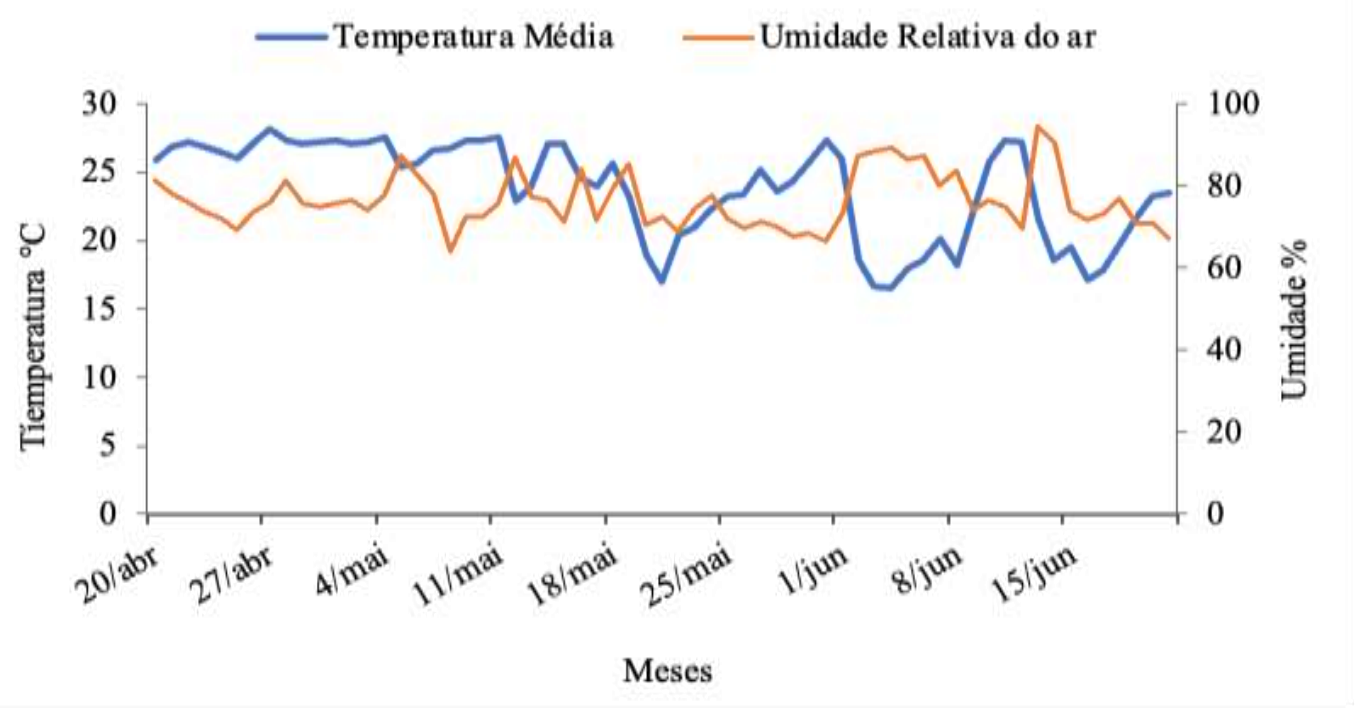

Fonte: Autores.

Segundo Gazzola et al. (2012) temperaturas entre 20 e $25^{\circ} \mathrm{C}$ são favoráveis, porém a temperatura ótima para o seu bom desenvolvimento situa-se entre 27 e $28^{\circ} \mathrm{C}$, enquanto a faixa de temperatura de 8 a $34^{\circ} \mathrm{C}$ é tolerada.

A umidade do ar é outro fator importante para a manutenção e viabilidade das flores, pois a cultura do girassol é propicia a doenças como a mancha da alternaria que causa diminuição da área fotossintética, formação de manchas foliares, desfolha precoce e consequentemente a morte da planta.

Os primeiros botões florais de girassol surgiram aos 36 dias após a semeadura, enquanto, o início da abertura das inflorescências ocorreu aos 43 dias após a semeadura, o que demostra precocidade no total abertura das inflorescências, comparado a estudos com genótipos de girassóis comerciais EMBRAPA 122 V/2000 e Sol Noturno que apresentaram abertura de flores aos 52,17 e 57,08 dias (De Andrade et al., 2012).

O girassol ornamental apresentou um período de desenvolvimento curto o que é uma característica vantajosa para a comercialização, houve diferença significativa para os diferentes substratos e tamanho de vasos testados, porém não foi observada interação entre os fatores. Verificou-se efeitos dos diferentes substratos sobre as variáveis diâmetro do caule, diâmetro do capítulo interno, altura da planta e durabilidade da inflorescência (Tabela 2).

Tabela 2. Médias do Diâmetro do Caule (DC), Diâmetro do Capítulo Interno (DCI), Diâmetro do Capítulo Externo (DCE), Altura da Planta (AP), Número de Folhas (NF) e Número de Botões (NB), Período de durabilidade da inflorescência (PDI) em diferentes substratos, Cáceres-MT, 2018.

\begin{tabular}{cccccccc}
\hline \multirow{2}{*}{ Tratamentos } & \multicolumn{7}{c}{ Variáveis analisadas } \\
\cline { 2 - 7 } & DC (mm) & DCI (mm) & DCE (mm) & AP (cm) & NF (un.) & NB (un.) & PDI (un.) \\
\hline Resíduo de Teca & $6,63 \mathrm{~b}$ & $40,07 \mathrm{~b}$ & $93,97 \mathrm{a}$ & $16,50 \mathrm{~b}$ & $11,50 \mathrm{a}$ & $1,52 \mathrm{a}$ & $10,65 \mathrm{~b}$ \\
Comercial & $7,52 \mathrm{a}$ & $46,21 \mathrm{a}$ & $100,59 \mathrm{a}$ & $18,45 \mathrm{a}$ & $12,05 \mathrm{a}$ & $2,22 \mathrm{a}$ & $12,62 \mathrm{a}$ \\
\hline $\mathrm{CV}(\%)$ & 9,81 & 17,96 & 15,63 & 15,29 & 14,63 & 26,63 & 10,05 \\
\hline
\end{tabular}

*Médias seguidas pela mesma letra na coluna não diferem entre si pelo teste de F, em nível de 5\% de probabilidade. Fonte: Autores. 
As plantas que obtiveram o maior diâmetro de caule foram as cultivadas no substrato comercial, apresentado caules resistentes e semelhantes aos resultados encontrados na literatura. Os resultados obtidos nesse estudo e os encontrados por Neves et al., (2008) em desenvolvimento de plantas de girassol em solo foram observados $8 \mathrm{~mm}$ de diâmetro de caule para a cultivar Sunbrigth, valores próximos aos parâmetros observados nesse trabalho

A altura da planta e uma das variáveis responsável pela indicação do valor comercial do girassol ornamental, ela é determinada pelo tamanho da planta desde a borda do vaso até a média final das hastes florais, medido pelo centro do vaso. A planta é classificada como A1 quando sua altura mínima for de $20 \mathrm{~cm}$ e a máxima de $40 \mathrm{~cm}$ e a classificada como A2 quando sua altura mínima for de $15 \mathrm{~cm}$ e a máxima $45 \mathrm{~cm}$. Outro critério que caracteriza a qualidade do lote, está estabelecido pela tolerância diferente para os defeitos graves e leves. Contudo, é fundamental plantas que apresentem um padrão comercial de qualidade e que sejam atrativas ao consumidor. $\mathrm{O}$ diâmetro do capítulo interno foi superior quando as plantas foram cultivadas no substrato comercial, enquanto não foram observadas diferenças com relação ao diâmetro do capítulo externo. Neves et al. (2008) trabalhando com a cultivar Sunbrigth obteve inflorescências menores do que $10 \mathrm{~cm}$, quando cultivados em solo, valores esse bem próximos aos obtidos no substrato comercial.

Wanderley et al. (2007) testando o efeito de paclobutrazol em cultivo hidropônico em genótipos de Girassol BRS Oásis alcançou médias para diâmetro de capítulo de $5,98 \mathrm{~cm}$ com uso da dose $0,5 \mathrm{mg} \mathrm{L}^{-1}$ do produto e em genótipos de Helio 358 médias de $6,28 \mathrm{~cm}$, assim sendo inferiores aos encontrados no nosso ensaio para os dois substratos testados.

A altura das plantas produzidas no substrato de resíduo de teca foi inferior ao tamanho das plantas produzidas no substrato comercial, mas apesar da diferença estatística o girassol produzido no substrato resíduo de teca encontra-se dentro do padrão de qualidade de comercialização A2 estipulado pelo Veiling Holambra (Veiling Holambra, 2018).

Para a variável número de folhas as plantas cultivadas no substrato comercial apresentaram média de 12 folhas por planta, esse resultado é inferior aos resultados por Barbosa et al. (2008) com o cultivo em substrato comercial variedade Golden com média de 14 folhas. Vale salientar que o híbrido Sunflower Sunbright Kids é uma cultivar de porte baixo (anão) o que pode ocasionar um menor número de folhas e um número de botões inferiores quando comparadas a uma cultivar de porte mais elevado.

$\mathrm{Na}$ avaliação da variável número de botões não ocorreu diferença significativa entre os substratos testados. O período de durabilidade das inflorescências encontradas no presente estudo foi em média de 12 dias para as plantas cultivadas em substrato comercial e de 10 dias para as plantas cultivados em resíduo de teca, ambos os valores superiores à média encontrada por Sato et al. (2010) em estudos com a cultivar Sunflower F1 Sumbrite Supreme verificou que as plantas de girassol se mantiveram em média 7 dias em condições de comercialização, fato esse que garante que a cultivar testada possui uma eficiência na manutenção de sua exuberância e beleza por um período maior.

No cultivo do girassol nos dois diferentes tamanhos de vaso, houve diferença significativa para as variáveis diâmetro do caule, diâmetro do capítulo interno e externo, altura da planta e número de botões. Na comparação dos tratamentos para as variáveis citada as plantas cultivadas no vaso de número 14 alcançaram os melhores índices de desenvolvimento (Tabela 3). 
Tabela 3. Médias do Diâmetro do Caule (DC), Diâmetro do Capítulo Interno (DCI), Diâmetro do Capítulo Externo (DCE), Altura da Planta (AP), Número de Folhas (NF) e Número de Botões (NB), Período de durabilidade da inflorescência (PDI) em diferentes volumes de substrato, Cáceres-MT, 2018.

\begin{tabular}{|c|c|c|c|c|c|c|c|}
\hline \multirow{2}{*}{ Tratamentos } & \multicolumn{7}{|c|}{ Variáveis analisadas } \\
\hline & $\mathrm{DC}(\mathrm{mm})$ & $\mathrm{DCI}(\mathrm{mm})$ & $\mathrm{DCE}(\mathrm{mm})$ & $\mathrm{AP}(\mathrm{cm})$ & NF (un.) & NB (un.) & PDI (dias) \\
\hline Vaso $\mathrm{n}^{\mathrm{o}} 10$ & $6,63 \mathrm{~b}$ & $40,09 \mathrm{~b}$ & $91,53 \mathrm{~b}$ & $16,82 \mathrm{~b}$ & $11,60 \mathrm{a}$ & $1,05 \mathrm{~b}$ & $12,00 \mathrm{a}$ \\
\hline Vaso $\mathrm{n}^{\circ} 14$ & $7,52 \mathrm{a}$ & 46,19 a & $103,03 \mathrm{a}$ & 18,13 a & $11,95 \mathrm{a}$ & $2,70 \mathrm{a}$ & $11,27 \mathrm{a}$ \\
\hline CV (\%) & 9,81 & 17,96 & 15,63 & 15,29 & 14,63 & 26,63 & 10,05 \\
\hline
\end{tabular}

*Médias seguidas pela mesma letra na coluna não diferem entre si pelo teste F, em nível de 5\% de probabilidade. Fonte: Autores.

Vários tamanhos de recipientes podem ser utilizados para se produzir mudas, sendo imprescindível que o vaso para o cultivo de girassol ornamental propicie plantas com hastes firmes, retas e com boa sustentação. $\mathrm{O}$ vaso n. $^{\circ} 14$ proporcionou um diâmetro de caule superior ao vaso $\mathrm{n}^{\circ} 10$ com uma média de 7,52 mm, bem próximos dos parâmetros estabelecidos de 8 mm cultivado em solo (Neves et al., 2008).

No setor de ornamental, vale salientar a importância do tamanho do capítulo, pois ele deve ser proporcional ao tamanho do vaso onde será produzido e comercializado. As médias para o diâmetro do capítulo interno e externo foram melhores nas plantas cultivadas no vaso $\mathrm{n}^{\mathrm{o}}$ 14. Os resultados neste estudo se assemelham com Neves et al. (2008), que encontraram diâmetros de inflorescências com médias de 8,6 cm e Carvalho et al., (2009) com diâmetro do capítulo de 9,55 $\mathrm{cm}$.

Sousa et al. (2011) em produção de zínia (Zinnia elegans (Jacq)) da família das Asteraceae em diferentes recipientes atingiu as melhores médias para a altura de $6,18 \mathrm{~cm}$ em recipiente com menor volume, contrário aos resultados encontrados no presente estudo em que os vasos de maior tamanho alcançaram a altura de $18,13 \mathrm{~cm}$ se sobressaindo em relação ao menor com 16,82 cm. Em estudos realizados por Pirola et al. (2015) em crisântemo (Dendranthema grandiflora (Tzvelev)), observou-se os melhores resultados para a altura da planta em cultivo com vasos maiores. É importante ressaltar que a altura das plantas obtidas no presente ensaio para os dois tipos de vasos testados, estão dentro do padrão de comercialização do Veiling Holambra (Veiling Holambra, 2018).

A média de folhas foi 12 por planta, independemente do tamanho do vaso utilizado. Sato et al. (2010) verificaram em cultivo com a cultivar Sunflower F1 Sumbrite Supreme uma média de 14 folhas, diferença está ocasionada provavelmente pelo uso de cultivares distintas, ou seja, uma questão genética. A maior produção de botões foi observada no vaso $\mathrm{n}^{\circ} 14$, sem variações na durabilidade das inflorescências.

\section{Conclusão}

A combinação substrato comercial e o vaso $\mathrm{n}^{\circ} 14$ se mostrou mais eficiente na produção de girassol ornamental Sunflower Sunbright Kids. Em ambos os substratos testados as plantas se enquadraram dento do padrão de comercialização A2 do Veiling Holambra.

\section{Referências}

Andrade, L.O., Gheyi, H.R., Dias, N.S., Nobre, R.G., Soares, F.A.L., \& Nascimento, E.C.S. (2014). Qualidade de flores de girassol ornamental irrigada com água residuária e doses de esterco. Revista Caatinga, 27(3), 142-149. 
Andrade, L.O., Gheyi, H.R., Nobre, R.G., Dias, N.S., \& Nascimento, E. C.S. (2012). Qualidade de flores de girassóis ornamentais irrigados com águas residuária e de abastecimento. Idesia (Arica), 30(2), 19-27. http://dx.doi.org/10.4067/S0718-34292012000200003

Barbosa, J.G., Barbosa, M.S., Tsuji, S.S., Muniz, M.A., Grossi, J.A.S., \& Rubim, M. (2008). Cultivo de girassol ornamental (Helianthus annuus L.) em vaso sob diferentes doses de paclobutrazol. Revista Brasileira de Horticultura Ornamental, 14(2), 205-208. https://doi.org/10.14295/rbho.v14i2.292

Carvalho Filho, J.L.S., Blank, A.M.F., Blank, A.F., \& Rangel, M.S.A. (2003). Produção de mudas de jatobá (Hymenaea courbaril L.) em diferentes ambientes, recipientes e composições de substratos. Cerne, $9(1), 109-118$.

Carvalho, M.P., Zanao Junior, L.A., Grossi, J.A.S., \& Barbosa, J.G. (2009). Silício melhora produção e qualidade do girassol ornamental em vaso. Ciência Rural, 39(8), 2394-2399. http://dx.doi.org/10.1590/S0103-84782009005000194

Castiglioni, V. B., Balla, A., Castro, C., \& Silveira, J.M. (1997). Fases de desenvolvimento da planta de girassol. Londrina: EMBRAPA-CNPSo, 24p. (EMBRAPA-CNPSo. Documentos, 59).

Ferreira, D.F. (2014). Sisvar: a Guide for its Bootstrap procedures in multiple comparisons. Ciência e Agrotecnologia, 38(2), 109-112.

Gazzola, A., Ferreira Jr, C.T.G., Cunha, D. A., Bortolini, E., Paiao, G. D., Primiano, I.V., Pestana, J., D’Andréa, M.S.C., \& Oliveira, M.S.A. (2012). Cultura do girassol. Piracicaba-SP.

Ibraflor. 2018. Instituto Brasileiro de Floricultura. Ano 09/ volume 87. http://www.ibraflor.com/site/>

INMET. 2018. Instituto Nacional de Meteorologia. <http://www.inmet.gov.br/portal/>

Lima, J.D., Moraes, W.S., Mendonça, J.C., \& Nomura., E.S. (2007). Resíduos da agroindústria de chá preto como substrato para produção de mudas de hortaliças. Ciência Rural, 37(6), 1609-1613. http://dx.doi.org/10.1590/S0103-84782007000600016.

Lorenzi, H., \& Souza, H. M. (2001). Plantas ornamentais do Brasil: arbustivas, herbáceas e trepadeiras. 3ed. Nova Odessa: Instituto Plantarum, 423p.

Neves, M.B., Buzetti, S., Castilho, R.M.M., \& Boaro, C.S.F. (2008). Desenvolvimento de plantas de girassol ornamental (Helianthus annuus L.) em vasos, em dois substratos com solução nutritiva e em solo. Científica, 33(2), 127-133. http://dx.doi.org/10.15361/1984-5529.2005v33n2p127+-+133

Neves, M.F., \& Pinto, M.J.A. (2015). Mapeamento e quantificação da cadeia de flores e plantas ornamentais do Brasil. São Paulo: OCESP.

Pelegrini, B. (1985). Girassol: Uma planta solar que das Américas conquistou o mundo. São Paulo: Ícone, 117p.

Pirola, K., Dotto, M., Wagner Junior, A., Alegretti, A.L., Conceição, P.C., \& Mendes, A.S. (2015). Recipientes e substratos na germinação e desenvolvimento de crisântemo e amor-perfeito. Revista Brasileira de Horticultura Ornamental, 21(2), 151-160. https://doi.org/10.14295/aohl.v21i2.485

Rodrigues, E.J.R., Pivetta, K.F.L., Castilho, R.M.M., Mattiuz, C.F.M., Batista, G.S., \& Grossi, J.A. S. (2012). Girassol. In: Paiva, P.D.O.; Almeida E.F.A.P. (Org.). Produção de flores de corte. Lavras - MG: UFLA, 1, 402-446.

Sato, O., Castro, A.M.C., Santos, K.H., Junior, A.C., Carvalho, F.K., \& Silva, D.P. (2010). Resíduos orgânicos na composição de substratos e no desenvolvimento do girassol ornamental. Revista Agrarian, 3(7), 18-23.

Seabra Júnior, S., Gadun, J., \& Cardoso, A.I.I. (2004). Produção de pepino em função da idade das mudas produzidas em recipientes com diferentes volumes de substrato. Horticultura Brasileira, 22(3), 610-613.

Sousa, H.H., Bezerra, F.C., Assis Júnior, R.N., Ferreira, F.V.M., Silva, T.C., \& Crisóstomo, L. A. (2011). Produção de mudas de Zínia elegans em substratos à base de resíduos agroindustriais e agropecuários em diferentes tamanhos de recipientes. Revista Brasileira de Horticultura Ornamental, 17(2), 115-120. https://doi.org/10.14295/rbho.v17i2.706

Veiling Holambra. 2018. Cooperativa Veiling Holambra. Disponível em: <http://www.veiling.com.br/ uploads/padrao/girassol-fv.pdf> Acesso em: 17 de outubro de 2018.

Wagner Júnior. A., Alexandre, R.S., Negreiros, J.R.S., Pimentel, L. D., Silva, J.O.C., \& Bruckner, C.H. (2006). Influência do substrato na germinação e desenvolvimento inicial de plantas de maracujazeiro amarelo (Passiflora edulis Sims f. flavicarpa Deg). Ciência e Agrotecnologia, 30(4), 643-647. http://dx.doi.org/10.1590/S1413-70542006000400008

Wanderley, C.S., Rezende, R., \& Andrade, C.A.B. (2007). Efeito de paclobutrazol como regulador de crescimento e produção de flores de girassol em cultivo hidropônico. Ciência e Agrotecnologia, 31(6), 1672-1678.

Zanello, C.A., \& Cardoso, J.C. (2016). Resíduo de grama como substrato para o cultivo orgânico de flores. Revista Ciência, Tecnologia \& Ambiente, 3(1), 3642. 